\title{
Large ionospheric disturbances during a minor geomagnetic storm on June 23, 2000
}

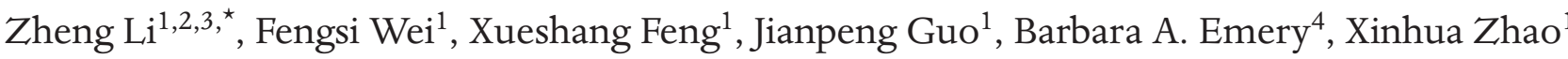 \\ ${ }^{1}$ SIGMA Weather Group, State Key Laboratory of Space Weather, CSSAR, Chinese Academy of Sciences, Beijing, China \\ ${ }^{2}$ Science and Technology on Aerospace Flight Dynamics Laboratory, Beijing, China \\ ${ }^{3}$ Beijing Aerospace Control Center, Beijing, China \\ ${ }^{4}$ High Altitude Observatory/NCAR, Boulder, CO, USA
}

\author{
Article history \\ Received October 3, 2011; accepted December 30, 2011. \\ Subject classification: \\ Ionospheric storm, Minor geomagnetic disturbance, Energy transfer.
}

\begin{abstract}
We investigate the variations in the ionosphere during a small geomagnetic storm on June 23, 2000, using the total electron content of the Jet Propulsion Laboratory global positioning system, and the ionospheric critical frequency. Large and long-lasting reductions in the daytime electron density were observed at mid-latitudes in the northern hemisphere by ionosondes. These reductions reached $30 \%$ to $40 \%$ compared to the $27-$ day median value. At the same time, a transformation from similar large positive storm effects to negative storm effects was observed in the northern hemisphere by the global positioning system receivers. The geomagnetic disturbance was very weak from June 23-25, 2000, as the SYM- $H$ index was $>-40 n T$ and ASY-H was $<90 n T$. Of note, during this case there were neither long-lasting southward IMF $\mathrm{B}_{\mathrm{z}}$ nor strong positive IMF $\mathrm{B}_{\mathrm{y}}$ components, where a large positive IMF $\mathrm{B}_{\mathrm{y}}$ might be the main reason for ionospheric storms during minor geomagnetic disturbances [Goncharenko et al. 2006]. We confirm a 13-h enhanced energy input from the disturbed solar wind by calculation of the Borovsky, Akasofu and Newell coupling functions, the global auroral precipitation, and the Joule heating. We suggest this enhanced energy input as the main cause of these intense ionospheric storms, although the maximum of the energy input was not large. In addition, we propose that the Newell coupling function might be more suitable for reflecting the energy transfer from the disturbed solar wind to the magnetosphere under weak geomagnetic activity.
\end{abstract}

\section{Introduction}

Ionospheric storms usually refer to intense disturbances of the total electron content (TEC) of the ionosphere and the ionospheric critical frequency (foF2), and they can be associated with magnetic disturbances that persist from several hours to days [e.g., Prölss 1993a, Prölss 1995, FullerRowell et al. 1996, Maruyama et al. 2004, Prölss 2006]. Therefore, these disturbances of the ionosphere form an important link in the complex chain of solar-terrestrial relations [Prölss 2006]. Ionospheric storms are often described as positive storms when the foF2 (or the TEC) is increased, and as negative storms when the foF2 (or the TEC) is significantly reduced. It is well known that there are two key parameters to define the spatial and temporal extent of the variations in the ionospheric density: (1) the highlatitude energy input from the solar wind, which is necessary to create high-latitude thermospheric disturbances, which lead to "composition bulges"; and (2) the horizontal neutral winds, which arise mainly from the pressure gradient force in the auroral oval and by ion drag at the polar cap, and are responsible for transporting these "composition bulges" to lower latitudes [see, e.g., Prölss 1980, Prölss 1987, Burns et al. 1991, Prölss 1993a, Buonsanto 1999, Fuller-Rowell et al. 2001, Goncharenko et al. 2006, Li et al. 2010].

These "composition bulges" are characterized by enhanced $\mathrm{N}_{2} / \mathrm{O}$, and will cause ionospheric negative storms by increasing the loss rate and decreasing the ionospheric electron density [Prölss 1981, Buonsanto 1999, Prölss and Werner 2002, Mendillo 2006]. For positive storms, their origin might be more complicated, and there remains no generally accepted explanation [Prölss 2006]. Two of the most frequently discussed mechanisms that have been proposed are: (1) changes in the neutral gas composition; and (2) upward transport of ionization. Both of these mechanisms rely on large-scale changes in the thermospheric circulation caused by heating in the auroral zone. According to the first mechanism [e.g., Rishbeth et al. 1987, Rishbeth 1991, Fuller-Rowell et al. 1997], the altered thermospheric circulation causes down-welling of neutral atomic oxygen through constant pressure surfaces at low-to-middle latitudes equator-ward of the composition disturbances zone, which increases the $\mathrm{O} / \mathrm{N}_{2}$ density ratio. These regions produce increases in the foF 2 and TEC. However, observational evidence for this supposition has been less conclusive. Prölss 
and Von Zahn [1977] found no evidence of any significant $\mathrm{O} / \mathrm{N}_{2}$ increases equator-ward of the disturbance zones using Esro 4 satellite data. Besides, Prölss [2006] suggested that the moderate increase in the $\mathrm{O} / \mathrm{N}_{2}$ density ratio frequently observed at middle or lower latitudes is certainly not sufficient to explain the rather large positive ionospheric storms in these regions. On the other hand, Burns et al. [1995] found evidence of large enhancements in the $\mathrm{O} / \mathrm{N}_{2}$ ratio in the evening sector using DE-2 satellite data during a geomagnetic storm. According to the second mechanism, in contrast, the idea that positive ionospheric storms are caused by lifting the ionization to greater heights is well supported by observations [Prölss 2006]. This mechanism is easily understood, because the loss rate is proportional to the $\mathrm{N}_{2}$ and $\mathrm{O}_{2}$ densities, and it decreases much faster with height than the production rate, which is proportional to the $\mathrm{O}$ density. Therefore, an upward displacement of the F layer will lead to an overall increase in the ionization density [Prölss 2006]. Mikhailov et al. [1995] suggested that this mechanism works best during the daytime, while increases in $\mathrm{O}$ density cause positive storm effects at night. However, what causes the uplifting of the plasma is an unanswered question [Prölss 2006]. Prölss [1997] found evidence that the uplifting of plasma was caused by enhanced equator-ward winds. On the other hand, scientists found that this upward motion of the ionosphere can also be caused by an enhanced-penetration eastward electric field [Tsurusani et al. 2004, Huang and Foster 2005, Pedatella et al. 2009]. In the case of equator-ward winds, the ionospheric plasma drifts along the magnetic field lines, which are directed upwards and equator-wards. In the case of an eastward electric field, we expect an $\vec{E} \times \vec{E}$ drift of the ionospheric plasma, which is directed upwards and polewards [Prölss 2006].

In the present study, we focus on ionospheric storms that are associated with minor geomagnetic storms. A number of studies have been carried out on the morphological, electro-dynamical and chemical processes of ionospheric storms under the conditions of intense geomagnetic storms over the past several decades [e.g., Prölss 1980, Prölss 1993b, Pi et al. 2000, Sastri et al. 2000, Tsagouri et al. 2000, Maruyama et al. 2004, Maruyama and Nakamura 2007, Zhao et al. 2008a]. However, recently, ionospheric storms during minor geomagnetic disturbances and under quiet geomagnetic conditions ( $Q$ disturbances) are getting more and more attention [e.g., Buonsanto et al. 1997, Mikhailov et al. 2004, Depueva et al. 2005, Goncharenko et al. 2006, Burešová and Laštovička 2007, Mikhailov et al. 2007a, Mikhailov et al. 2007b, Zhao et al. 2008b]. Large variations in the ionosphere that are induced by minor geomagnetic disturbances are complicated and hard to explain, because of the weak energy injection from the solar wind. Buonsanto et al. [1997] compared four models with the Millstone Hill incoherent scatter radar and Fabry-Perot interferometer measurements during a minor geomagnetic storm, when $K p$ reached a maximum of $5+$. Goncharenko et al. [2006] revealed two cases of ionospheric negative storms at mid-latitudes when the minimal values of the SYM-H index were $-32 \mathrm{nT}$ and $-48 \mathrm{nT}$, and suggested that the strong positive interplanetary magnetic field $B_{y}$ might have an important role in the transport of the disturbed gas composition with reduced $\mathrm{O} / \mathrm{N}_{2}$. Zhao et al. [2008b] reported anomalous enhancement of ionospheric electron content in the Asian-Australian region under low geomagnetic activity, and considered a continuously enhanced eastward electric field as the main cause of this effect.

During the period of June 23-25, 2000, a minor geomagnetic disturbance (SYM-H $=-39 \mathrm{nT}$ ) and intense ionospheric positive and negative storms occurred. The TEC in the northern hemisphere increased more than $100 \%$ in the positive storm, and reduced by ca. $70 \%$ in the negative storm, while the foF2 of the northern hemisphere ionosonde stations reduced by $17 \%$ to $37 \%$ compared to the 27 -day median value. The goal of the present study is to determine the origin of the ionospheric storms, by investigating the chain of "disturbed solar wind-geomagnetic disturbancesionospheric disturbances". Our study suggests that these large variations are caused by a 13-h enhanced energy injection from the disturbed solar wind.

\section{Datasets and analysis method}

The solar wind magnetic field and plasma parameters from June 22-25, 2000, are available from the 1-h-averaged OMNI database at $1 \mathrm{AU}$ (in GSM coordinates). These variables are: (1) the north-south component of IMF $B_{z}$; (2) the IMF $B_{\mathrm{y}}$; and (3) the dawn-to-dusk component of the interplanetary electric field $E_{\mathrm{y}}$. In additional, we calculate three coupling functions: the Borovsky function [Borovsky 2008, Guo et al. 2010], the Akasofu function [Akasofu 1981] and the Newell function [Newell et al. 2007]. These are often written as:

$$
\begin{gathered}
R=0.4 \mu_{0}^{1 / 2} \sin (\theta / 2) \rho v^{2}\left(1+0.5 M_{m s}^{-2}\right)\left(1+\beta_{s}\right)^{-1 / 2} \\
\cdot\left[C \rho+\left(1+\beta_{s}\right)^{-1 / 2} \rho_{m}\right]^{-1 / 2}\left[\left(1+\beta_{s}\right)^{1 / 2}+1\right]^{-1 / 2} \\
\varepsilon=\frac{4 \pi}{\mu_{0}} l_{0}^{2} \nu B^{2} \sin ^{4} \frac{\theta}{2} \\
F_{N}=v^{4 / 3} B_{T}^{2 / 3} \sin ^{8 / 3}(\theta / 2)
\end{gathered}
$$

respectively. The variables $\theta, \rho, B, B T, v$ and $l_{0}$ on the righthand side are given in SI units, and denote the IMF clock angle, mass density, solar wind magnetic field magnitude, solar wind magnetic field magnitude perpendicular to the Sun-Earth line, solar wind velocity, and a scaling factor, respectively. The scaling factor $l_{0}$ was empirically determined 
to be $7 \mathrm{R}_{\mathrm{E}}$ [Perreault and Akasofu 1978]. In addition, the variables $\beta_{s}, M_{m s}, C$ in Equation (1) are the plasma beta of the magnetosheath near the nose of the magnetosphere:

$$
\beta_{s}=3.2 \times 10^{-2} M_{A}^{1.92}
$$

and the compression ratio of the bow shock:

$$
C=\left\{(1 / 4)^{6}+\left[1 /\left(1+1.38 \log _{e}\left(M_{A}\right)\right)\right]^{6}\right\}^{-1 / 6}
$$

the magnetosonic Mach number of the solar wind:

$$
M_{m s}=v /[(B / 4 \pi \rho)+2 P / \rho]^{1 / 2}
$$

where $P$ is the particle pressure (thermal plus kinetic) in the upstream solar wind and $M_{A}$ is the Alfvén Mach number:

$$
\cdot M_{A}=v(4 \pi \rho)^{1 / 2} / B
$$

The level of geomagnetic activity during the period examined is indicated by the SYM-H, ASY-H, polar cap (PC) index and Dst. These geomagnetic indices are obtained from the World Data Center for Geomagnetism, Kyoto (http: / / swdcwww.kugi.kyoto-u.ac.jp/index.html). The SYM-H is essentially the same as the Dst index, except for its higher resolution and the slightly different magnetic stations from which the data are gathered. The ASY-H is a good indicator of auroral substorm activity [Iyemori and Rao 1996]. The PC index, which is derived from polar magnetic variations, is primarily a measure of the intensity of the transpolar ionospheric currents that are generated by the solar wind interactions with the Earth magnetosphere [Guo et al. 2011].

Global auroral precipitation estimates are computed using data provided by the Defense Meteorological Satellite Program (DMSP) and the National Oceanic and Atmospheric Administration (NOAA) satellites, which were intercalibrated with each other by Emery et al. [2008, 2009]. The NOAA satellites provide estimates of the total hemispheric power ( $\mathrm{HPt}$ ) from both electron and ion sensors for energies less than $20 \mathrm{keV}$, while the DMSP satellites provide estimates of the electron hemispheric power (HPe) from the electron sensors for energies less than $20 \mathrm{keV}$, ignoring the highest energy channel between 20.62 $\mathrm{keV}$ and $30.18 \mathrm{keV}$ [Emery et al. 2008]. In the present study, we calculate the global auroral ion $(\mathrm{Pi})$ and electron $(\mathrm{Pe})$ inputs from the sum of the hourly HPi and HPe estimates from each hemisphere, because the seasonal variations, IMF $B_{\mathrm{Z}}$ responses, and solar rotational amplitudes are different between ions and electrons [Emery et al. 2008, 2011]. Moreover, we confine ourselves to auroral energies less than $20 \mathrm{keV}$ for the present study.

Joule heating in megawatts is estimated using relations that were derived by Knipp et al. [2004]:
$J H_{s}=29.27|P C|+8.18 P C^{2}-0.04|D s t|+0.0126 D s t^{2}$

$J H_{e}=29.14|P C|+2.54 P C^{2}-0.21|D s t|+0.0023 D s t^{2}$

$J H_{w}=13.36|P C|+5.08 P C^{2}-0.48|D s t|+0.0011 D s t^{2}$

The variables PC and Dst on the right-hand side denote the PC index and the Dst index, respectively. $\mathrm{JH}_{\mathrm{s}}, \mathrm{JH}_{\mathrm{e}}$ and $\mathrm{JH}_{\mathrm{w}}$ represent the Joule heating in summer, at the equinox and in winter, respectively. Summer is defined as April 21 to August 20, winter as October 21 to February 20, and the equinox as February 21 to April 20, and August 21 to October 20. In the present study, a Joule heating estimate for the summer is added to a winter estimate to obtain a global value.

The hourly values of the foF 2 of the ionosonde stations at mid-latitudes are obtained from the SPIDR (Space Physics Interactive Data Resource, available at http:/ / spidr.ngdc. noaa.gov/spidr/) network of the National Geophysical Data Center. These ionosonde stations are Eglin AFB $\left(30.4^{\circ} \mathrm{N}\right.$, $\left.86.7^{\circ} \mathrm{W}\right)$, Grahamstown $\left(33.3^{\circ} \mathrm{S}, 26.5^{\circ} \mathrm{E}\right)$, Learmonth $\left(21.9^{\circ} \mathrm{S}\right.$, $\left.114.0^{\circ} \mathrm{E}\right)$, Port Stanley $\left(51.7^{\circ} \mathrm{S}, 57.8^{\circ} \mathrm{W}\right)$, Rome $\left(41.7^{\circ} \mathrm{N}\right.$, $\left.12.5^{\circ} \mathrm{E}\right)$, Tashkent $\left(41.3^{\circ} \mathrm{N}, 69.6^{\circ} \mathrm{E}\right)$, and Wallops Is. $\left(37.9^{\circ} \mathrm{N}\right.$, $\left.75.5^{\circ} \mathrm{W}\right)$. We collected the data of the TEC from the GPS with global ionospheric maps retrieved at the Jet Propulsion Laboratory (JPL) [Mannucci et al. 1998]. There is a rich literature describing the use of the JPL GPS TEC in studies of ionospheric behavior, particularly under disturbed conditions [Ho et al. 1998, Liu et al. 2010]. In our investigations, we used the global ionospheric map data provided by JPL with a two-hour temporal resolution and a spatial grid of $5^{\circ}$ in longitude and $2.5^{\circ}$ in latitude to calculate the $\triangle \mathrm{TEC}$, which is the relative deviation of the TEC from the quiet level:

$$
\Delta T E C=\frac{T E C-T E C_{27 m}}{T E C_{27 m}} \times 100 \%
$$

Here the TEC is the two-hourly value of the perturbed TEC, and $\mathrm{TEC}_{27 \mathrm{~m}}$ represents the 27 -day TEC running mean value centered on the day in question.

\section{Results}

\subsection{Interplanetary and geomagnetic conditions}

Figure 1 shows several indices that describe the interplanetary and geomagnetic conditions for June 22-25, 2000: IMF $B_{z}$ (Figure 1a), IMF $B_{y}$ (Figure 1b), the dawn-todusk component of the interplanetary electric field, $E_{\mathrm{y}}$ (Figure 1c), the SYM-H index (Figure 1d), and the ASY-H index (Figure 1e). As shown in Figure 1d, the small geomagnetic storm of June 23-25, 2000, began with a prominent sudden storm commencement (SSC) observed at around 1300 UT on June 23 , and the magnetic field started to decrease monotonically from 1800-2000 UT, and reached 


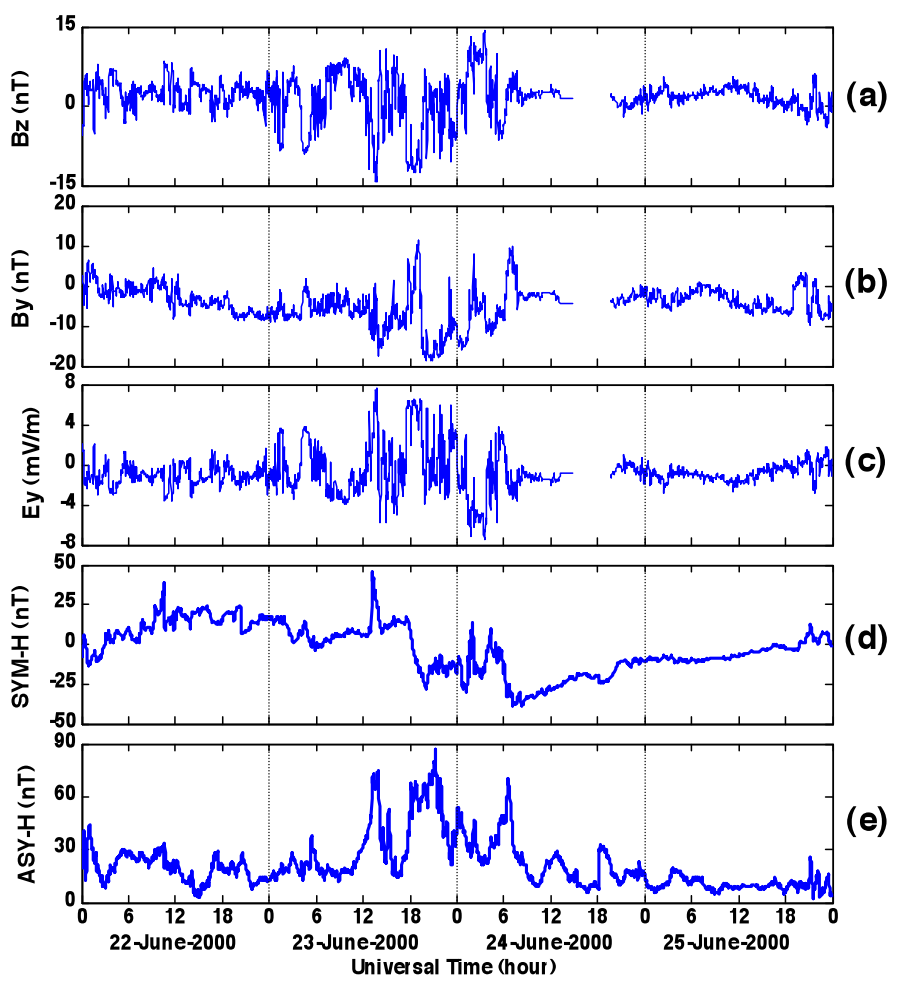

Figure 1. Interplanetary and geomagnetic conditions for the period of June 22-25, 2000. (a) IMF $B_{z}$. (b) IMF $B_{y^{\text {. }}}$ (c) Dawn-to-dusk component of the interplanetary electric field, $E_{\mathrm{y}}$. (d) SYM-H index. (e) ASY-H index.
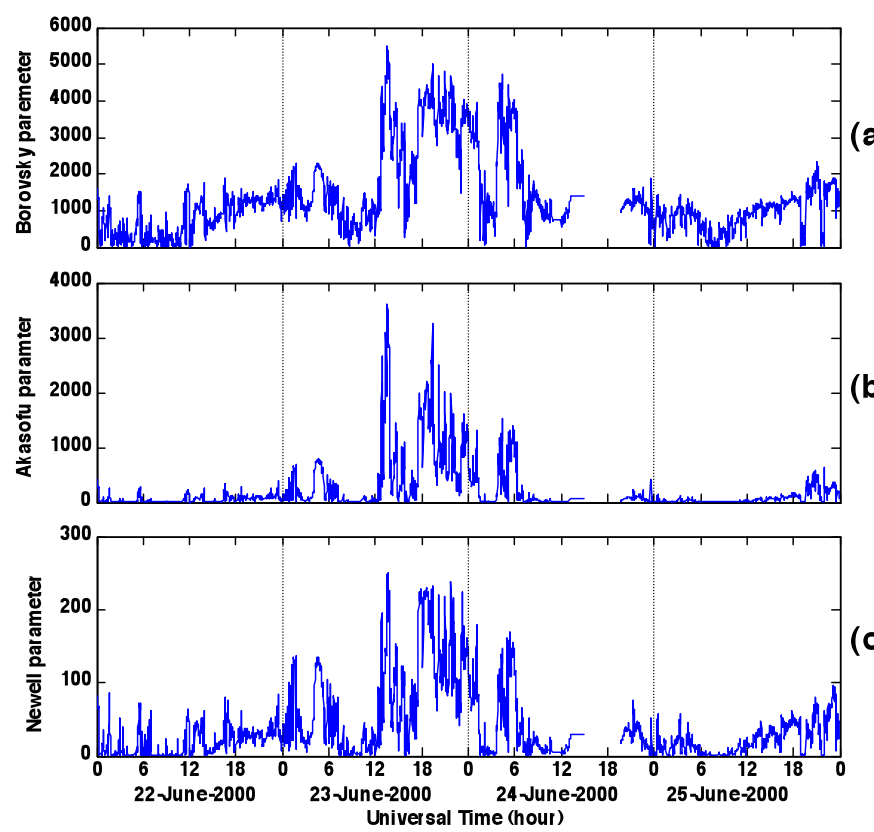

Figure 2. Solar wind energy input using coupling functions for June 22-25, 2000. (a) The Borovsky parameter. (b) The Akasofu parameter. (c) The Newell parameter.

$-28 \mathrm{nT}$ at 2000 UT. From 2000 UT on June 23, to 0600 UT on June 24, the SYM-H index oscillated between $-30 \mathrm{nT}$ and $14 \mathrm{nT}$ (Figure 1d). After these oscillations, it decreased abruptly and reached its maximum depression of $-39 \mathrm{nT}$ at 0700 UT on June 24 . This was followed by a slow recovery throughout the rest of June 24 , and it was back to positive values around 2000 UT on June 25 (Figure 1d). According to the geomagnetic storm classification of Gonzalez et al. [1994], these disturbances can be regarded as a weak storm. The ASY-H index increased with the onset of the magnetic storm, and reached its maximum of $87 \mathrm{nT}$ during the main phase of the storm (Figure 1e). The important feature in this case is that the IMF $B_{z}$ (Figure 1a) and IMF $B_{y}$ (Figure 1b) did not have long-lasting southward and positive components, respectively. The only noticeable IMF $B_{z}$ southward component occurred at around 1730 UT on June 23 , and lasted no more than $3 \mathrm{~h}$. We have not included the effects of the IMF $B_{\mathrm{y}}$ fluctuations on the meridional wind in our analysis, because of its relatively short time with a positive component and the thermospheric response.

\subsection{Solar wind energy input and dissipation in the} thermosphere-ionosphere system

Figure 2 shows the solar wind energy input using the Borovsky (Figure 2a), Akasofu (Figure 2b), and Newell (Figure 2c) parameters for the period of June 22-25, 2000. The Borovsky parameter trends in similar ways to the Akasofu and Newell parameters: it began to enhance with the onset of the storm at 1300 UT on June 23, and showed three peaks with the period of around 1300-1600 UT on June 23,1730 UT on June 23 to 0200 UT on June 24 , and 0300 0700 UT on June 24 . Note that these increases persist in the coupling functions for $13 \mathrm{~h}$ at least. Among these coupling functions, on average, the enhancement of the Borovsky parameter is largest, while the enhancement of the Akasofu parameter is relatively weak.

Figure 3 shows the auroral precipitation $(\mathrm{Pt}=\mathrm{Pi}+\mathrm{Pe}$ for $<20 \mathrm{keV}$ ) (Figure 3, top) and the Joule heating (Figure 3, bottom) for June 22-25, 2000. Both the auroral precipitation and the Joule heating increased at around 1300 UT on June 23, which corresponds to the SSC. The greatest enhancement of the auroral precipitation was ca. $130 \mathrm{GW}$, at around 1900 UT on June 23, while the Joule heating had three peaks, with values of ca. $450 \mathrm{GW}$ at around $1330 \mathrm{UT}$ on June 23, 1900 UT on June 23, and 0000 UT on June 24. Compared with the statistical results for intense geomagnetic storms (Dst $<-100 \mathrm{nT}$ ) [Guo et al. 2011], the maxima of the auroral precipitation and Joule heating for this study are reduced by ca. $25 \%$ and ca. $55 \%$. Similar to the coupling functions, the important feature in this case is the timescale of the energy deposited in the thermosphere-ionosphere system, which remained for ca. $13 \mathrm{~h}$, with the prominent enhancement starting around 1300 UT on June 23.

\subsection{Ionosonde and total electron content observations}

The behavior of the foF 2 of seven mid-latitude ionosondes for June 22-25, 2000, are shown in Figure 4, as solid lines for the foF2, and as broken lines for the reference foF2, which are the 27-day median values. The ionosondes in Figure $4 \mathrm{a}-\mathrm{d}$ are located in the northern hemisphere, while 


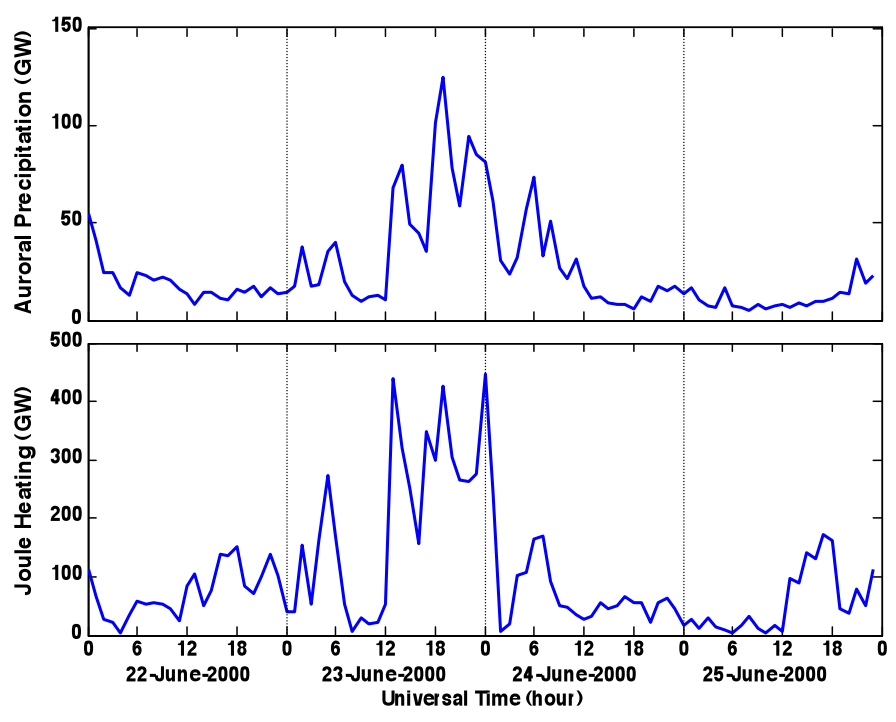

Figure 3. Solar wind energy in thermosphere-ionosphere system for June 22-25, 2000. Top: Auroral precipitation. Bottom: Joule heating.

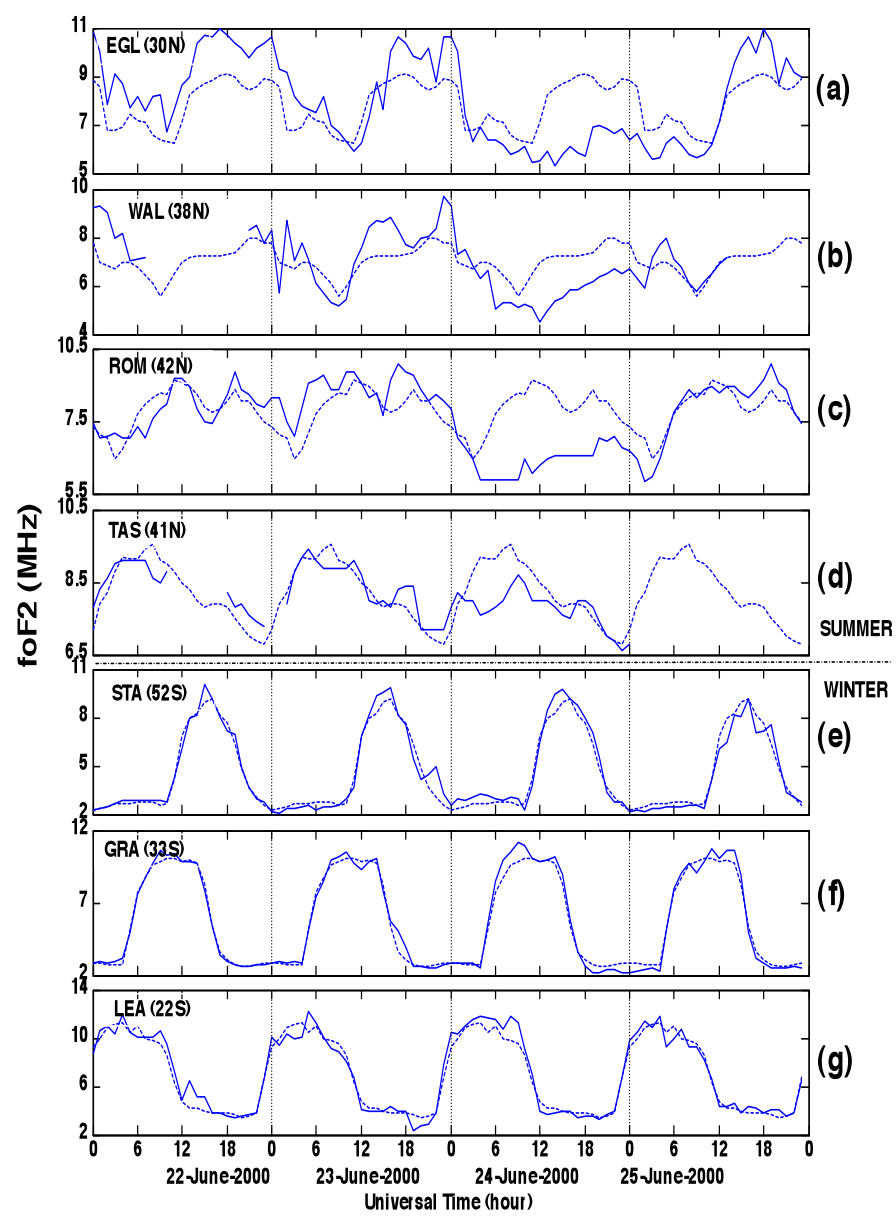

Figure 4. From top to bottom: The foF2 at the ionosondes for June 22-25, 2000: (a) Eglin AFB (EGL); (b) Wallops Is. (WAL); (c) Rome (Rom); (d) Tashkent (TAS); (e) Port Stanley (STA); (f) Grahamstown (GRA); and (g) Learmonth (LEA). Solid lines, observed foF2. Broken lines, reference foF2 (27-day running median).

the ionosondes of Figure 4e-f are located in the southern hemisphere. A significant reduction in the foF 2 , which began at around 0200-0400 UT on June 24, was seen at the four ionosonde stations located in the northern hemisphere. The
foF2 of the ionosondes from Figure $4 \mathrm{a}-\mathrm{d}$ decreased by $-37.83 \%,-34.98 \%,-34.04 \%$, and $-17.39 \%$, respectively, compared with the reference. Moreover, the negative disturbances persist ca. $32 \mathrm{~h}, 24 \mathrm{~h}, 25 \mathrm{~h}$, and $16 \mathrm{~h}$, respectively, in these ionosondes. It should be noted that although these relative reductions in the foF 2 are not very large, they can also be regarded as intense negative storms, because the reference foF 2 are large as: (1) the study occurred at the solar maximum; (2) the northern hemisphere is in summer; and (3) the maximum reductions occurred in the local daytime. On the other hand, there are no prominent ionospheric disturbances observed by the three ionosondes located in the southern hemisphere, as shown in Figure 4e-f.

Figure $5 \mathrm{a}-\mathrm{c}$ shows the $\triangle \mathrm{TEC}$ maps with two-hour temporal resolution on June 23,24 and 25 , respectively. The color bar defines the relative changes in the TEC. As shown in Figure 5a, a significant positive disturbance was seen for the nightside of the northern hemisphere between $\left(50^{\circ} \mathrm{N}\right.$, $\left.55^{\circ} \mathrm{E}\right)$ and $\left(85^{\circ} \mathrm{N}, 150^{\circ} \mathrm{E}\right)$ at around $1500 \mathrm{UT}$. The local times at these longitudes were between 1830 LT on June 23 and 0100 LT on June 24. From 1700-1900 UT, the positive effects expanded to higher and lower latitudes, and almost extended over the entire nightside, where the local times were between 1800 LT on June 23 and 0600 LT on June 24. The map for 2100 UT on June 23 should be noted, because an intense positive effect occurred in the morning sector of the northern hemisphere at mid- and high latitudes, which increased more than $100 \%$ compared with the 27 -day running median value (Figure 5a). At 2300 UT shown in Figure 5a, the positive disturbances were observed at almost all longitudes of the northern hemisphere. In general, the positive effects were observed at high latitudes for the nightside and at mid- and low latitudes for the dayside. These positive disturbances, as shown in Figure $5 \mathrm{~b}$, remained at mid- and low latitudes of the northern hemisphere, but weakened over time in the period of 0100-0900 UT on June 24. After 1100 UT on June 24, there is no significant largescale and long-lasting enhancement observed by the GPS receivers.

On the other hand, prominent negative variations were seen in the auroral zone in the southern hemisphere starting at around 2100 UT on June 23, as shown in Figure 5a,b. These negative effects penetrated to ca. $45^{\circ} \mathrm{S}$ for the nightside, and continued until 0300 UT on June 24 . The significant negative storms in the northern hemisphere shown in Figure 5b,c were observed from 0500 UT on June 24 to 0300 UT on June 25 . These negative variations were first at high latitudes and later expanded to middle latitudes, but did not expand to low latitudes, which is different from the positive perturbations described above. However, the negative effects are also intense, with the greatest reductions reaching ca. $70 \%$ by 0100 UT on June 25 . Note that the negative disturbances in both the northern hemisphere and 
LI ET AL.
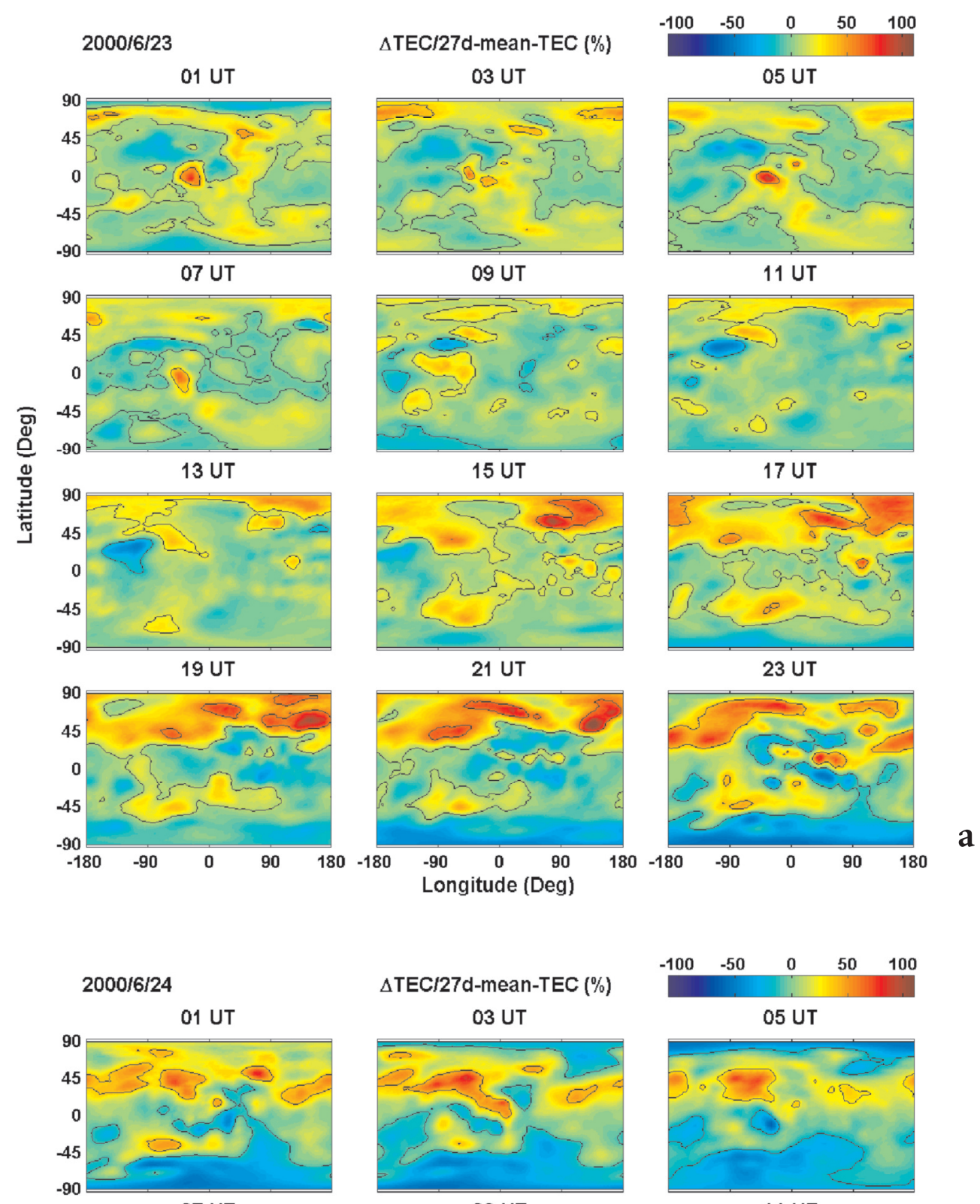

O9 UT
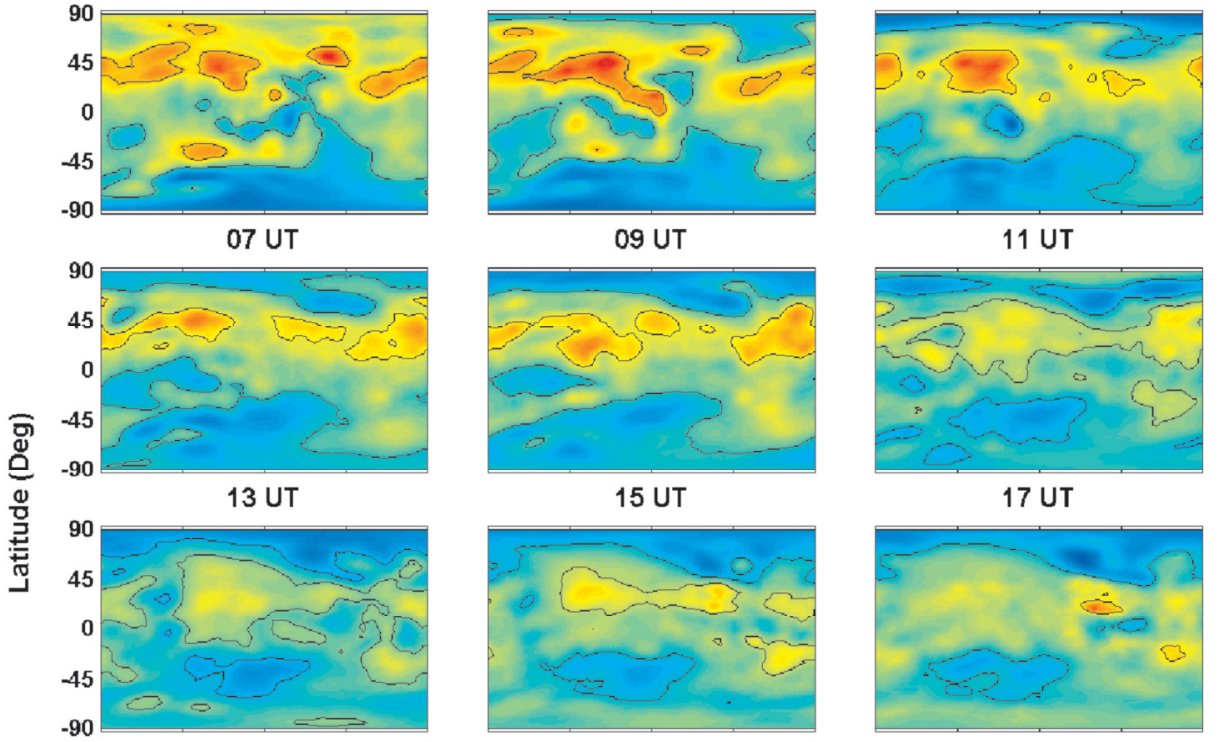

11 UT
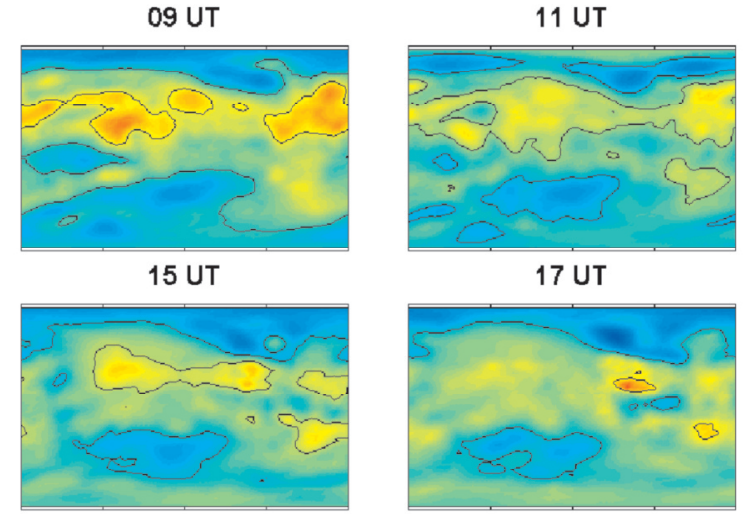

21 UT

23 UT
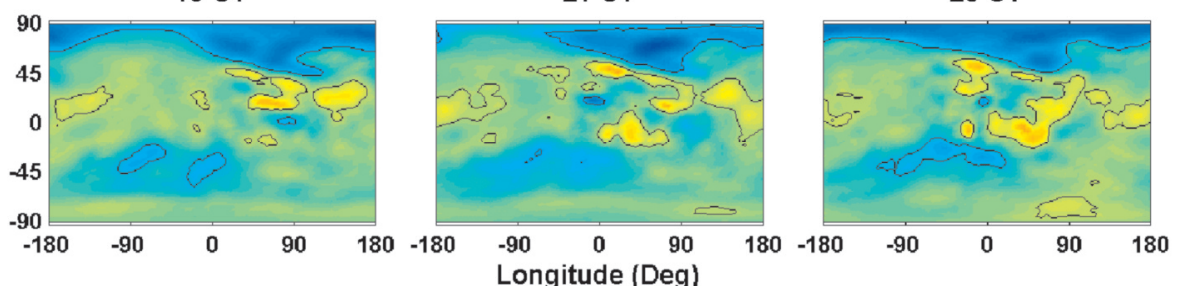

b

Figure 5. (a) $\triangle \mathrm{TEC}$ maps with two-hour temporal resolution showing the temporal and spatial evolution of the ionospheric storm on June 23,2000 . (b) As for (a), for June 24, 2000. (c) As for (a), for June 25, 2000 (see next page). 


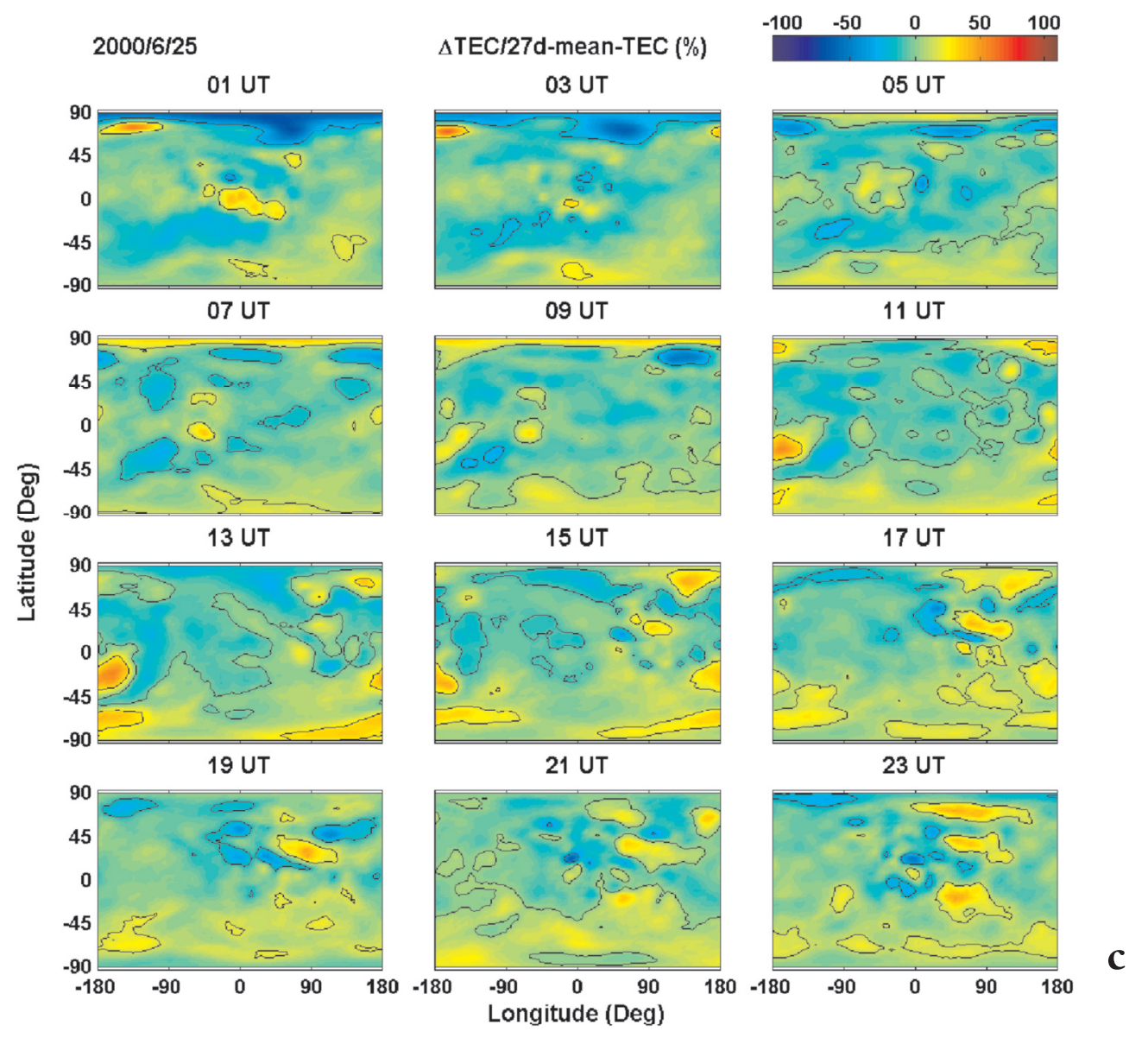

Figure $\mathbf{5 c}$. See caption on previous page.

the southern hemisphere were more intense and expanded to lower latitudes during the local night-time. Indeed, the large-scale and intense disturbance regions in the northern hemisphere were observed in the dusk-to-midnight sectors before 1700 UT on June 24 , and later in the midnight-todawn sectors until 0300 UT on June 25.

Summing up, negative storms in the foF 2 were observed by the mid-latitude ionosondes located in the northern hemisphere on the second day after the onset of the geomagnetic storm. These reductions reached $17 \%$ to $38 \%$ compared with the quiet-time values, and lasted ca. $16 \mathrm{~h}$ to $32 \mathrm{~h}$ for different ionosonde stations. In addition, a positive storm in the TEC occurred in the northern hemisphere with a 2-h delay from the geomagnetic SSC. These positive effects persisted for ca. $18 \mathrm{~h}$, and turned to negative effects that gradually started at $0500 \mathrm{UT}$ on June 24 , which lasted until 0300 UT on June 25 , with the greatest decrease of ca. $70 \%$. On the other hand, in the southern hemisphere, short-lasting negative effects were observed in the TEC, but not in the foF2.

\section{Discussion}

The experimental data given above from ground-based and space-based instruments show that under favorable conditions, even small geomagnetic storms can cause significant variations in the ionosphere at middle and lower latitudes. The main features of this event can be summarized as follows: (1) The geomagnetic disturbance was weak, as the SYM-H index was $>-40 \mathrm{nT}$ and ASY-H index was $<90 \mathrm{nT}$, while the IMF $B_{z}$ and IMF $B_{y}$ did not have long-lasting southward and strong positive components, respectively. (2) Both the coupling functions (Borovsky, Akasofu, Newell) and the satellite measurements (auroral precipitation, Joule heating) indicated an enhancement of the high-latitude energy input that started with the SSC and persisted for ca. 13 h. (3) Prominent negative storms (>17\%-38\%) in the foF 2 at middle latitudes in the northern hemisphere lasted for 16 $\mathrm{h}$ to $32 \mathrm{~h}$ in different ionosondes. (4) Large positive variations $(>100 \%)$ in the TEC, which lasted for ca. $18 \mathrm{~h}$, occurred with a 2-h delay from the onset of the magnetic storm in the high and middle latitudes of the northern hemisphere, and even expanded to low latitudes later. These then gradually turned to negative effects, which were at high and middle latitudes, and persisted for $\mathrm{ca} .22 \mathrm{~h}$, with the greatest reduction of ca. $70 \%$. These features can be clearly identified in Figures 1-5.

In actual ionospheric storms, disturbances are a mixture of several processes, and the leading mechanism might vary from hour to hour, and the significance of each process might differ from event to event [Fuller-Rowell et al. 1994, Maruyama et al. 2004]. Bounsanto et al. [1997] compared four models with Millstone Hill incoherent scatter radar and Fabry-Perot interferometer measurements during a minor geomagnetic storm when $\mathrm{Kp}$ reached a maximum of $5+$. 
They suggested that the positive effects in the ionosphere might be due to a decrease in the $\mathrm{O}^{+}$recombination rate caused by the higher hmF2, combined with the compressional effect of a traveling atmosphere disturbance and an enhanced downward flux of $\mathrm{O}^{+}$ions. Two intense negative storms at middle latitudes under minor geomagnetic disturbances in April 2002 were investigated by Goncharenko et al. [2006]. In these cases, the minimal values of the SYM-H index were $-32 \mathrm{nT}$ and $-48 \mathrm{nT}$. Large and long-lasting reductions in the daytime electron density were observed during the geomagnetic storms at middle latitudes and even at low latitudes, using incoherent scatter radars, ionosondes, and GPS receivers. An important feature in these cases is that the direction of the IMF $B_{\mathrm{y}}$ component was strong and longlasting positive, while the IMF $B_{z}$ remained mostly southward during this period. As the configuration of the convection pattern at high latitudes is affected by the sign and magnitude of the IMF $B_{\mathrm{y}}$, and a strong and positive $B_{\mathrm{y}}$ will cause stronger zonal winds at high latitudes, which lead to stronger equator-ward winds at lower latitudes [FullerRowell and Rees 1984, Rees et al. 1986, Weimer 1995], Goncharenko et al. [2006] suggested that the strong positive IMF $B_{\mathrm{y}}$ might have an important role in the transport of the disturbed gas composition with reduced $\mathrm{O} / \mathrm{N}_{2}$, which later caused intense negative ionospheric storms. Another ionospheric storm under low geomagnetic activity in June 2002 was reported by Zhao et al. [2008b] using a GPS receiver network and a chain of ionosondes distributed around the Asian-Australian sector. In their case, after local sunset, the $\mathrm{NmF} 2$ at low latitudes was seen to increase by $200 \%$, while the geomagnetic environment was quiet, as the SYM-H index was $>-20 \mathrm{nT}$ under conditions of constant northward IMF $B_{z}$ and positive but not strong IMF $B_{\mathrm{y}}$. Zhao et al. [2008b] suggested that a continuously enhanced eastward electric field might be the main cause of the ionospheric positive effect at low latitudes.

However, our case is relatively different from those mentioned above. The IMF $B_{\mathrm{y}}$ component almost always remained negative in this case. Furthermore, the effects of the eastward electric field are also weak in our case, because the ionospheric disturbances were first observed at high latitudes and the ionosphere in the equatorial region was relatively quiet. Now the key point is: what caused these intense and long-lasting ionospheric positive and negative storms? A prominent enhancement of energy injection from the solar wind began with the SSC at around 1300 UT on June 23, 2000, and persisted for ca. $13 \mathrm{~h}$, as shown in Figures 2 and 3 , which we suggest is the main cause of the ionospheric storms, although the peak values of the energy input were not large.

These enhanced energy inputs caused considerable heating of the upper atmosphere in the auroral zone, which led to the disturbed horizontal neutral winds. The disturbed horizontal winds enhanced the night-time equator-ward thermospheric winds, which were restrained by the poleward winds and were weaker during the local daytime [e.g., Buonsanto 1999]. The enhanced thermospheric winds uplifted the ionosphere and then led to ionospheric positive effects for the local night-time at 1500 UT on June 23, as Figure 5a shows. With the continuous injection of energy, the equator-ward winds were enhanced gradually, and the positive effects expanded to lower latitudes. After 2100 UT on June 23 , the positive disturbances were also observed for the local daytime, due to the enhanced equator-ward neutral winds and the rotation of the Earth, which might have carried the effects of the ionosphereic storm to the morning sector [e.g., Fuller-Rowell et al. 2001]. As shown in Figures 2 and 3, the energy input decreased sharply after 0000 UT on June 24. We find that the ionospheric positive storm weakened over time after 0100 UT on June 24, and finally vanished at $1100 \mathrm{UT}$.

As indicated by the TEC in the southern hemisphere and the foF 2 , the ionospheric negative storm in this case first occurred at around 2300 UT on June 23, 2000, in the southern hemisphere, and at mid-latitudes in the northern hemisphere at around 0300 UT on June 24, 2000. These observations indicate that the disturbed gas zone was formed at 2300 UT on June 23 , and then was carried by meridional winds to mid-latitudes in the northern hemisphere at 0300 UT on June 24. However, the positive effects in the northern hemisphere were still observed for these regions and at this time in the TEC maps. That is not surprising, because the TEC is the quantity integrated along the vertical line, while the foF 2 is the local quantity at the $\mathrm{F}$ layer peak [Maruyama and Nakamura 2007]. From the TEC maps shown in Figure $5 \mathrm{a}-\mathrm{c}$, and similar to the positive storms, these ionospheric negative disturbances were stronger and expanded to lower latitudes at local mid-latitudes due to the stronger meridional winds. These meridional winds carried the disturbance zone to lower latitudes, which are characterized by enhanced $\mathrm{N}_{2} / \mathrm{O}$, and then caused negative storms by increasing the loss rate and decreasing the ionospheric electron density.

The ionosphere in the southern hemisphere was relatively quiet during the geomagnetic storm, because no significant and long-lasting disturbances were observed in either the foF 2 or the TEC. The reason for this is that the meridional winds are weak in the winter hemisphere [e.g., Prölss 1980], the ionosphere at mid-latitudes in the southern hemisphere was not uplifted, and the negative effects were restrained to higher latitudes. Comparing Figures 2 and 3, we suggest that the Newell function might be a better reflection of the energy input under weak geomagnetic activity.

\section{Conclusions}

We present here a case study of large ionospheric storm effects measured by the foF 2 and the TEC under a weak 
geomagnetic storm that started from June 23,2000 . In this case, the SYM-H index reached a minimum of $-39 \mathrm{nT}$ and the ASY-H index was $\leq 90 \mathrm{nT}$. Moreover, there was no longlasting southward IMF $B_{z}$ or strong positive $B_{\mathrm{y}}$, as observed by the WIND spacecraft. Large ionospheric disturbances are not usually observed under such conditions.

However, both the JPL GPS TEC and the foF2 showed significant ionospheric positive and negative storms in the northern hemisphere during the geomagnetic disturbances. For the positive storm, the TEC increased by $100 \%$, and the positive effects persisted for ca. $18 \mathrm{~h}$. For the negative storm, the daytime foF 2 decreased by $17 \%$ to $38 \%$, and the negative effects lasted for $16 \mathrm{~h}$ to $32 \mathrm{~h}$ at mid-latitudes, while the reduction in the TEC reached $70 \%$ and lasted for $22 \mathrm{~h}$. In addition, the positive perturbations in the TEC extended to the equatorial regions.

By analyzing the coupling functions, Joule heating and auroral precipitation, we find a 13-h enhanced energy input from the solar wind, which we consider as the main cause of the ionospheric storms. These long-lasting enhanced energy inputs lead to an enhanced equator-ward meridional wind and area of increased $\mathrm{N}_{2} / \mathrm{O}$. The meridional winds uplifted the ionosphere and caused positive storms, and the disturbed gas area caused negative storms later.

Hence, such large variations in the ionosphere, which rarely occur during minor geomagnetic storms, might have been caused by the wind mechanisms and composition, both of which were associated with the long-lasting energy input in the auroral zone. Our results show that under favorable conditions, a weak geomagnetic storm can also cause intense disturbances in the ionosphere.

Acknowledgements. The OMNI solar wind database is compiled by the Space Physics Data Facility at the Goddard Space Flight Center. The geomagnetic data were provided from the World Data Center, Kyoto. The original DMSP and NOAA satellite auroral hemispheric power estimates were obtained from the USAF Research Laboratory, Hanscom AFB, MA, USA, and from the Space Weather Prediction Center, Boulder, CO, USA, via the Coupling, Energetics and Dynamics of Atmospheric Regions (CEDAR) database. Additional NOAA ion and electron hemispheric powers were supplied by David S. Evans of the Space Weather Prediction Center at the National Oceanic and Atmospheric Administration (NOAA). We thank the Jet Propulsion Laboratory, California Institute of Technology, for offering the global ionospheric TEC maps. We also thank B. Zhao for his assistance in revising this paper. This work is jointly supported by the National Natural Science Foundation of China (40890162, 40921063, 41031066, 40874091, and 40874077) and the Specialized Research Fund for State Key Laboratories.

\section{References}

Akasofu, S.-I. (1981). Energy coupling between the solar wind and the magnetosphere, Space Sci. Rev., 28, 121.

Borovsky, J.E. (2008). The rudiments of a theory of solar wind/magnetosphere coupling derived from first principles, J. Geophys. Res., 113, A08228; doi:10.1029/2007JA 012646.

Buonsanto, M.J., M. Codrescu, B.A. Emery, C.G. Fesen, T.J.
Fuller-Rowell, D.J. Melendez-Alvira and D.P. Sipler (1997). Comparison of models and measurements at Millstone Hill during the January 24-26, 1993, minor storm interval, J. Geophys. Res., 102, 7267-7277; doi:10.1029/96JA02602. Buonsanto, M.J. (1999). Ionospheric storms - a review, Space Sci. Rev., 88, 563-601.

Burešová, D., and J. Laštovička (2007). Pre-storm enhancements of foF2 above Europe, Adv. Space Res., 39, 12981303; doi:10.1016/j.asr.2007.03.003.

Burns, A., T. Killeen and R. Roble (1991). A theoretical study of thermospheric composition perturbations during an impulsive geomagnetic storm, J. Geophys. Res., 96, 14153-14167.

Burns, A.G., T.L. Killeen, G.R. Carignan and R.G. Roble (1995). Large enhancements in the $\mathrm{O} / \mathrm{N}_{2}$ ratio in the evening sector of the winter hemisphere during geomagnetic storms, J. Geophys. Res., 100, 14,661-14,671; doi:10.1029/94JA03235.

Depueva, A. Kh., A.V. Mikhailov and V.Kh. Depuev (2005). Quiet time F2-layer disturbances at geomagnetic equator, Int. J. Geomagn. Aeron., 5, GI3001; doi:10.1029/2004GI 000071.

Emery, B.A., V. Coumans, D.S. Evans, G.A. Germany, M.S. Greer, E. Holeman, K. Kadinsky-Cade, F.J. Rich and W. $\mathrm{Xu}$ (2008). Seasonal, $\mathrm{Kp}$, solar wind, and solar flux variations in long-term single-pass satellite estimates of electron and ion auroral hemispheric power, J. Geophys. Res., 113, A06311; doi:10.1029/2007JA012866.

Emery, B.A., I.G. Richardson, D.S. Evans, R.J. Rich and W. $\mathrm{Xu}$ (2009). Solar wind structure sources and periodicities of global electron hemispheric power over three solar cycles, J. Atmos. Sol. Terr. Phys., 71, 1157-1175; doi:10.1016/ j.jastp.2008.08.005.

Emery, B.A., I.G. Richardson, D.S. Evans, F.J. Rich and G. Wilson (2011). Solar rotation periodicities and the semiannual variation in the solar wind, radiation belt, and aurora, In: M.M. Bisi, B.A. Emery, and B.J. Thompson (eds.), The Sun-Earth Connection near Solar Minimum, Special issue of Solar Phys.; doi:10.1007/s11207-011-9758-x.

Fuller-Rowell, T.J., and D. Rees (1984). Interpretation of an anticipated long-lived vortex in the lower thermosphere following simulation of an isolated substorm, Planet. Space Sci., 32, 69-85; doi:10.1016/0032-0633(84)90043-6.

Fuller-Rowell, T.J., M.V. Codrescu, R.J. Moffett and S. Quegan (1994). Response of the thermosphere and ionosphere to geomagnetic storms, J. Geophys. Res., 99, 3893-3914; doi:10.1029/93JA02015.

Fuller-Rowell, T.J., M.V. Codrescu, H. Rishbeth, R.J. Moffett and S. Quegan (1996). On the seasonal response of the thermosphere and ionosphere to geomagnetic storms, J. Geophys. Res., 101, 2343-2353.

Fuller-Rowell, T.J., M.V. Codrescu, R.G. Roble and A.D. Richmond (1997). How does the thermosphere and iono- 
sphere react to a geomagnetic storm?, In: B.T. Tsurutani, W.D. Gonzales, Y. Kamide and J.K. Arbllo (eds.), Magnetic Storms, Geophysical Monograph 98, American Geophysical Union, Washington, D.C.

Fuller-Rowell, T.J., M.V. Codrescu and E. Araujo-Pradere (2001). Capturing the storm-time F-region ionospheric response in an empirical model, Geophysical monograph, 125, 393-401.

Goncharenko, L., J. Salah, G. Crowley, L. J. Paxton, Y. Zhang, A. Coster, W. Rideout, C. Huang, S. Zhang, B. Reinisch and V. Taran (2006). Large variations in the thermosphere and ionosphere during minor geomagnetic disturbances in April 2002 and their association with IMF By, J. Geophys. Res., 111, A03303; doi:10.1029/2004JA010683.

Gonzalez, W.D., J.A. Joselyn, Y. Kamide, H.W. Kroehl, G. Rostoker, B.T. Tsurutani and V.M. Vasyliunas (1994). What is a geomagnetic storm?, J. Geophys. Res., 99, 57715792; doi:10.1029/93JA02867.

Guo, J., X. Feng, J. Zhang, P. Zuo and C. Xiang (2010). Statistical properties and geoefficiency of interplanetary coronal mass ejections and their sheaths during intense geomagnetic storms, J. Geophys. Res., 115, A09107; doi:10.1029/2009JA015140.

Guo, J., X. Feng, B.A. Emery, J. Zhang, C. Xiang, F. Shen and W. Song (2011). Energy transfer during intense geomagnetic storms driven by interplanetary coronal mass ejections and their sheath regions, J. Geophys. Res., 116, A05106; doi:10.1029/2011JA016490.

Ho, C., A. Mannucci, L. Sparks, X. Pi, U. Lindqwister, B. Wilson, B. Iijima and M. Reyes (1998). Ionospheric total electron content perturbations monitored by the GPS global network during two northern hemisphere winter storms, J. Geophys. Res., 103, 26409-26420.

Huang, C.S., and J.C. Foster (2005). Long-duration penetration of the interplanetary electric field to the low-latitude ionosphere during the main phase of magnetic storms, J. Geophys. Res., 110, A11309; doi:10.1029/2005JA011202.

Iyemori, T., and D.R.K. Rao (1996). Decay of the Dst field of geomagnetic disturbance after substorm onset and its implication to storm-substorm relation, Annales Geophysicae, 14, 608-618.

Knipp, D.J., W.K. Tobiska and B.A. Emery (2004). Direct and indirect thermospheric heating sources for solar cycles 2123, Solar Phys., 224, 495-505.

Li, Z., F.S. Wei, X.S. Feng and X.H. Zhao (2010). The "same side-opposite side effect" of the heliospheric current sheet in ionospheric negative storms, Solar Phys., 263, 263-273; doi:10.1007/s11207-010-9559-7.

Liu, L., M. He, X. Yue, B. Ning and W. Wan (2010). Ionosphere around equinoxes during low solar activity, J. Geophys. Res., 115, A09307; doi:10.1029/2010JA015318.

Mannucci, A.J., B.D. Wilson, D.N. Yuan, C.M. Ho, U.J. Lindqwister and T.F. Runge (1998). A global mapping technique for GPS derived ionospheric total electron content measurements, Radio Sci., 33, 565-582.

Maruyama, T., G. Ma and M. Nakamura (2004). Signature of TEC storm on 6 November 2001 derived from dense GPS receiver network and ionosonde chain over Japan, J. Geophys. Res., 109, A10302; doi:10.1029/2004JA010451.

Maruyama, T., and M. Nakamura (2007). Conditions for intense ionospheric storms expanding to lower midlatitudes, J. Geophys. Res., 112, A05310; doi:10.1029/2006JA 012226.

Mendillo, M. (2006). Storms in the ionosphere: patterns and processes for total electron content, Rev. Geophys., 44, RG4001; doi:10.1029/2005RG000193.

Mikhailov, A.V., M.G. Skoblin and M. Förster (1995). Daytime F2-layer positive storm effect at middle and lower latitudes, Annales Geophysicae, 13, 532-540; doi:10.1007/ s00585-995-0532-y.

Mikhailov, A.V., A.Kh. Depueva and T.Yu. Leschinskaya (2004). Observations of neutral winds and electric fields using backscatter from field-aligned irregularities, Int. J. Geomagn. Aeron., 5, GI1006; doi:10.1029/2003GI000058.

Mikhailov, A.V., V.H. Depuev and A.H. Depueva (2007a). Daytime F2-layer negative storm effect: what is the difference between storm-induced and Q-disturbance events?, Annales Geophysicae, 25, 1531-1541; doi:10.5194/ angeo-25-1531-2007.

Mikhailov, A.V., V.H. Depuev and A.H. Depueva (2007b). Synchronous NmF2 and NmE daytime variations as a key to the mechanism of quiet-time F2-layer disturbances, Annales Geophysicae, 25, 483-493.

Newell, P.T., T. Sotirelis, K. Liou, C.-I. Meng and F.J. Rich (2007). A nearly universal solar wind-magnetosphere coupling function inferred from 10 magnetospheric state variables, J. Geophys. Res., 112, A01206; doi:10.1029/2006 JA012015.

Pedatella, N.M., J. Lei, K.M. Larson and J.M. Forbes (2009). Observations of the ionospheric response to the 15 December 2006 geomagnetic storm: long-duration positive storm effect, Geophys. Res. Lett., 114, A12313; doi:10.1029/ 2009JA014568.

Perreault, P., and S.-I. Akasofu (1978). A study of geomagnetic storms, J. Roy. Astronom. Soc., 54, 547.

Pi, X., M. Mendillo, W.J. Hughes, M.J. Buonsanto, D.P. Sipler, J. Kelly, Q. Zhou, G. Lu and T.J. Hughes (2000). Dynamical effects of geomagnetic storms and substorms in the middle-latitude ionosphere: an observational campaign, J. Geophys. Res., 105, 7403-7417, doi:10.1029/1999JA900460.

Prölss, G.W., and U. Von Zahn (1977). Seasonal variations in the latitudinal structure of atmospheric disturbances, J. Geophys. Res., 82, 5629-5632.

Prölss, G.W. (1980). Magnetic storm associated perturbations of the upper atmosphere: recent results obtained by satelliteborne gas analyzers, Rev. Geophys. Space Phys., 18, 183-202. 
Prölss, G.W. (1981). Latitudinal structure and extension of the polar atmospheric disturbance, J. Geophys. Res., 86, 2385-2396; doi:10.1029/JA086iA04p02385.

Prölss, G.W. (1987). Storm-induced changes in the thermospheric composition at middle latitudes, Planet. Space Sci., 35, 807-811.

Prölss, G.W. (1993a). On explaining the local time variation of ionospheric storm effects, Annales Geophysicae, 11, 1-9.

Prölss, G.W. (1993b). Common origin of positive ionospheric storms at middle latitudes and the geomagnetic activity effect at low latitudes, J. Geophys. Res., 98, 5981-5991.

Prölss, G.W. (1995). Ionospheric F-region Storms, In: H. Volland (ed.), Handbook of Atmospheric Electrodynamics, CRC Press, Boca Raton, Fla., 2, 195-248,

Prölss, G.W. (1997). Magnetic storm associated perturbations of the upper atmosphere, In: B.T. Tsurutani, W.D. Gonzalez, Y. Kamide, and J.K. Arballo (eds.), Magnetic Storms, Geophys. Monogr., 98, 227-241.

Prölss, G.W. (2006). Ionospheric F-region Storms: Unsolved Problems, In Characterising the Ionosphere, Meeting Proceedings RTO-MP-IST-056, Paper 10, 10-1-10-20, Neuilly-sur-Seine, France: RTO.

Prölss, G.W., and S. Werner (2002). Vibrationally excited nitrogen and oxygen and the origin of negative ionospheric storms, J. Geophys. Res., 107, 1016; doi:10.1029/2001JA 900126.

Rees, D., T.J. Fuller-Rowell, R. Gordon, M.F. Smith, N.C. Maynard, J.P. Heppner, N.W. Spencer, L. Wharton, P.B. Hays and T.L. Killeen (1986). A theoretical and empirical study of the response of the high latitude thermosphere to the sense of the "Y" component of the interplanetary magnetic field, Planet. Space Sci., 34, 1-40.

Rishbeth, H., T.J. Fuller-Rowell and D. Rees (1987). Diffusive equilibrium and vertical motion in the thermosphere during a severe magnetic storm: a computational study, Planet. Space Sci., 35, 1157-1165.

Rishbeth, H. (1991). F-region storms and thermospheric dynamics, J. Geomagn. Geoelectr., 43, 513-524.

Sastri, J.H., N. Jyoti, V.V. Somayajulu, H. Chandra and C.V. Devasia (2000). Ionospheric storm of early November 1993 in the Indian equatorial region, J. Geophys. Res., 105, 18443-18455; doi:10.1029/ 1999JA000372.

Tsagouri, I., A. Belehaki, G. Moraitis and H. Mavromichalaki (2000). Positive and negative ionospheric disturbances at middle latitudes during geomagnetic storms, Geophys. Res. Lett., 27, 3579-3582.

Tsurutani, B., A. Mannucci, B. Iijima, M.A. Abdu, J. Humberto, A. Sobral, W. Gonzalez, F. Guarnieri, T. Tsuda, A. Saito, K. Yumoto, B. Fejer, T.J. Fuller-Rowell, J. Kozyra, J.C. Foster, A. Coster and V.M. Vasyliunas (2004). Global dayside ionospheric uplift and enhancement associated with interplanetary electric fields, J. Geophys. Res., 109, A08302; doi:10.1029/2003JA010342.
Weimer, D.R. (1995). Models of high-latitude electric potentials derived with a least error fit of spherical harmonic coefficients, J. Geophys. Res., 100, 19595-19607; doi:10.1029/ 95JA01755.

Zhao, B., W. Wan, K. Tschu, K. Igarashi, T. Kikuchi, K. Nozaki, S. Watari, G. Li, L.J. Paxton, L. Liu, B. Ning, J.-Y. Liu, S.Y. Su and H.P. Bulanon (2008a). Ionosphere disturbances observed throughout southeast Asia of the superstorm of 20-22 November 2003, J. Geophys. Res., 113, A00A04; doi:10.1029/2008JA013054.

Zhao, B., W. Wan, L. Liu, K. Igarashi, M. Nakamura, L.J. Paxton, S.-Y. Su, G. Li and Z. Ren (2008b). Anomalous enhancement of ionospheric electron content in the Asian-Australian region during a geomagnetically quiet day, J. Geophys. Res., 113, A11302; doi:10.1029/2007JA 012987.

\footnotetext{
${ }^{\star}$ Corresponding author: Zheng Li, SIGMA Weather Group, State Key Laboratory of Space Weather, CSSAR, Chinese Academy of Sciences, Beijing, China; email: zli@spaceweather.ac.cn.

C 2012 by the Istituto Nazionale di Geofisica e Vulcanologia. All rights reserved.
} 